Proc. Indian Acad. Sci. (Chem. Sci.), Vol. 112, No. 1, February 2000, pp. 43-49

(C) Indian Academy of Sciences

\title{
Topological estimation of proton-ligand formation constants of potential antitumour agents: Salicylhydroxamic acids
}

\author{
SNEHA KARMARKAR ${ }^{1}$, P V KHADIKAR ${ }^{1}$ *, VIJAY K AGRAWAL ${ }^{2}$, \\ KESHAV C MATHUR ${ }^{2}$, MANORAMA MANDLOI ${ }^{3}$ \\ and SHOBHA JOSHI ${ }^{3}$ \\ ${ }^{1}$ Research Division, Laxmi Pest \& Fumigation Pvt. Ltd., 3 Khatipura, \\ Indore 452 007, India \\ ${ }^{2}$ Department of Chemistry, APS University, Rewa 486 003, India \\ ${ }^{3}$ Department of Chemistry, Model Holkar Science College, Indore, 452001 \\ India \\ e-mail: pvkhadikar@yahoo.com
}

MS received 20 October 1999

\begin{abstract}
Proton-ligand formation constants of salicylhydroxamic acids (SHA) and their nuclear substituted derivatives have been estimated topologically using the normalized Wiener index, referred to as mean square Wiener index (Wms). Regression analysis of the data indicates that Wms can be used successfully for estimating and monitoring proton-ligand formation constants.
\end{abstract}

Keywords. Salicylhydroxamic acids; antitumour agents; topological indices; normalized Wiener index; mean square Wiener index.

\section{Introduction}

Selective inhibition by salicylhydroxamic acid (SHA) of deoxyribonucleic acid (DNA) synthesis in Ehrlich ascites tumour cells has been reported ${ }^{1}$. Characteristics of the inhibition were similar in some respects to those of hydroxyureas and of oxamylhydroxyamic acids ${ }^{2,3}$. Effects on the synthesis of DNA and of protein were nominal and were considered to be of secondary nature as a consequence of the lower rate of DNA formation. The inhibition of SHA was further evident immediately upon adding the compound to the cells, that is, no preincubation was necessary to evoke this effect. The rate of DNA synthesis resembled the control rate upon removal of the inhibitor by washing the cells, indicating no firm binding to the cells and no irreversible alteration of the cell by the compounds.

Gale and Hyenes ${ }^{4}$ have shown that the structural features of compounds related to SHA influence the course of nucleic acid synthesis in a tumour-cell test system.

The physico-chemical and pharmacological potential of salicylhydroxamic acid and its nuclear substituted derivatives is determined by their corresponding protonation constants. These protonation constants in turn can be correlated with some of the topological indices.

*For correspondence 
Prompted by the aforementioned observations ${ }^{5}$, salicylhydroxamic acid and its nuclear substituted derivatives were synthesized and their protonation constants were assessed.

Application of topology and graph theory has indicated that the structure of an organic molecule acting as a drug can be represented by a number like the numerical presentation of their physico-chemical and pharmacological properties ${ }^{5,6}$. The molecular topological approach in quantitative structure-activity relationship (QSAR) essentially involves translation of molecular structures into characteristic numerical descriptors known as topological indices for predicting pharmacological activities. The advantage of topological indices is that they may be used directly in QSAR.

In view of the above, the work herein described was initiated for estimating the proton-ligand formation constants of salicylhydroxamic acids from the normalized Wiener index named as mean square Wiener indices (Wms). Our earlier study ${ }^{4}$ indicated that the normalized Wiener index gives better results than the Wiener index itself. Different types of normalized Wiener indices can be obtained by imposing different types of normalization conditions. The definition of the normalized Wiener index used in the present study and its potential in modelling the proton-ligand formation constants of SHA derivatives is described below.

\section{Methodology used}

As stated above, it is known that certain invariants of molecular graphs, usually referred to as topological indices, can be used for establishing QSAR of interest in pharmacology. A number of successful QSAR studies were made ${ }^{4}$ based on Wms by means of which we can determine the ways in which the structural features of SHA and SHA derivatives influence the course of nucleic acid synthesis in a tumour cell test system.

According to graph theory and topology 7,8 , molecular structure of the organic molecules is transformed into a molecular graph wherein atoms constituting the molecules are termed as vertices and bonds joining the atoms are termed as edges. The vertices (atoms) are depicted by a dot (.) or a small circle (O), while the edges (bonds) are represented by lines (-). In doing so, all the carbon-hydrogen bonds are suppressed. Such molecular graphs are called hydrogen-suppressed molecular graphs or simply molecular graphs.

The molecular structure and molecular graph of the parent salicylhydroxamic acid (SHA) are as shown in figure 1.

It is worth recording that in the molecular graph the distance between the two vertices (atoms) is equal to the number of edges (bonds) in the shortest unit path connecting the respective vertices (atoms). These distances ${ }^{9,10}$ are defined as the elements of a real $\mathrm{N} \times \mathrm{N}$ matrix $D(G)$, which is known as the distance matrix, where $N$ is the number of vertices (atoms) in molecular graph $G$. The elements of the distance matrix, $D_{i j}(G)$, are integers, for $i, j$ neighbours and the matrix is given by the expression:

$\boldsymbol{a}$

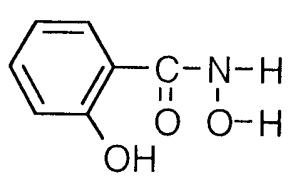

$b$

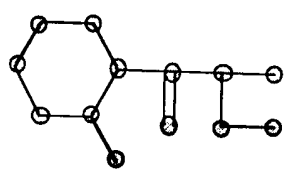

Figure 1. Molecular structure (a) and molecular graph (b) of SHA. 


$$
D_{i j}(G)=\mid \begin{aligned}
& 1, \text { for } i \neq j, \\
& 0, \text { for } i=j .
\end{aligned}
$$

The distance matrix is symmetric in relation to the principal diagonal and thus can be divided into two triangular off-diagonal submatrices. The total number of elements ${ }^{11}$ in a triangular off-diagonal submatrice is equal to $\frac{1}{2} N(N-1)$.

The mean-square Wiener index (Wms) is defined as the mean of the square of the elements $D_{i j}(G)$ of the off-diagonal submatrix:

$$
\mathrm{Wms}=\frac{1}{N(N-1)} \sum_{i j} D_{i j}^{2} .
$$

Experimental protonation constants of SHA and its derivatives are determined by a potentiometric method proposed earlier ${ }^{12,13}$.

It should be mentioned that SHA has the formula given in figure 1 and is expected to dissociate in two steps:

$$
\begin{aligned}
& \mathrm{H}_{2} \mathrm{~A} \rightleftharpoons \mathrm{H}^{+}+\mathrm{HA}^{-}, \\
& \mathrm{HA}^{-} \rightleftharpoons \mathrm{H}^{+}+\mathrm{A}^{2-} .
\end{aligned}
$$

In the dianion $\mathrm{A}^{2-}$, both the hydroxamic and the phenolic $\mathrm{OH}$ groups lose a proton. In the monoanion form the proton is dissociated from the hydroxamic function $(\mathrm{NHOH})$. There is equilibrium between the two forms, each of the monoanionic species being stabilized by very strong intramolecular hydrogen bonds.

Hence, the proton-ligand formation equilibrium can be expressed as shown below and the logarithmic representation of their formations is given by their respective equilibrium constants (i.e. $\log p k_{1}{ }^{\mathrm{H}}$ and $\log p k_{2}{ }^{\mathrm{H}}$ respectively.

$$
\begin{aligned}
& \mathrm{H}^{+}+\mathrm{A}^{2-} \rightleftharpoons \mathrm{HA}^{-}, \\
& \mathrm{HA}^{-}+\mathrm{H}^{+} \rightleftharpoons \mathrm{H}_{2} \mathrm{~A} .
\end{aligned}
$$

\section{Results and discussion}

SHA and its derivatives, their abbreviations and their protonation constants are recorded in table 1. Values of $\mathrm{Wms}$ as calculated from (2) for SHA-derivatives are also summarized in table 1. Regression parameters for the correlations of Wms with the proton-ligand formation constants are given in table 2. Table 3 records the experimental and estimated proton-ligand formation constants together with the difference between their experimental and estimated values.

In table 1 are also listed the logarithms of the so-called ${ }^{12,13}$ practical protonation constants $p K_{1}{ }^{\mathrm{H}}$ and $p K_{2}{ }^{\mathrm{H}}$ of the respective salicylhydroxamic acids. The protonation constants for SHA-derivatives pertain to the equilibria below:

$$
p K_{1}^{\mathrm{H}}=\frac{\left[\mathrm{HA}^{-}\right]}{\left[\mathrm{A}^{2-}\right]\left[\mathrm{H}^{+}\right]},
$$


Table 1. SHA derivatives, their abbreviations, mean square Wiener index and experimental protonation constants $\left(\log p K_{1}^{\mathrm{H}}\right.$ and $\left.\log p K_{2}^{\mathrm{H}}\right)$.

\begin{tabular}{|c|c|c|c|c|}
\hline \multirow[b]{2}{*}{ Compound } & \multirow[b]{2}{*}{ Abbrev. } & \multirow{2}{*}{$\begin{array}{l}\text { Mean square } \\
\text { Wiener index }\end{array}$} & \multicolumn{2}{|c|}{$\begin{array}{l}\text { Protonation } \\
\text { constants }\end{array}$} \\
\hline & & & $\log p K_{1}^{\mathrm{H}}$ & $\log p K_{2}{ }^{\mathrm{H}}$ \\
\hline Salicylhydroxamic acid & SHA & $55 \cdot 16$ & $9 \cdot 28$ & $6 \cdot 18$ \\
\hline 3-Amino-salicylhydroxamic acid & 3-ASHA & $83 \cdot 38$ & $7 \cdot 68$ & 4.96 \\
\hline 5-Amino-salicylhydroxamic acid & 5-ASHA & $87 \cdot 54$ & $7 \cdot 68$ & 4.96 \\
\hline 3,5-Diamino-salicylhydroxamic acid & 3,5-DASHA & $114 \cdot 20$ & $7 \cdot 68$ & 4.96 \\
\hline 3-Bromo-salicylhydroxamic acid & 3-BSHA & $62 \cdot 02$ & $7 \cdot 29$ & $4 \cdot 18$ \\
\hline 5-Bromo-salicylhydroxamic acid & 5-BSHA & $63 \cdot 72$ & $7 \cdot 29$ & $4 \cdot 18$ \\
\hline 3,5-Dibromo-salicylhydroxamic acid & 3,5-DBSHA & $70 \cdot 05$ & $6 \cdot 90$ & $3 \cdot 40$ \\
\hline 3-Chloro-salicylhydroxamic acid & 3-CSHA & $62 \cdot 02$ & $7 \cdot 31$ & $4 \cdot 22$ \\
\hline 5-Chloro-salicylhydroxamic acid & 5-CSHA & $63 \cdot 72$ & $7 \cdot 31$ & $4 \cdot 22$ \\
\hline 3,5-Dichloro-salicylhydroxamic acid & 3,5-DCSHA & $70 \cdot 05$ & $6 \cdot 94$ & $3 \cdot 48$ \\
\hline 3-Fluoro -salicylhydroxamic acid & 3-FSHA & $62 \cdot 02$ & $7 \cdot 34$ & $4 \cdot 28$ \\
\hline 5-Fluoro-salicylhydroxamic acid & 5-FSHA & $63 \cdot 72$ & $7 \cdot 34$ & $4 \cdot 28$ \\
\hline 3,5-Difluoro-salicylhydroxamic acid & 3,5-DFSHA & $70 \cdot 05$ & $7 \cdot 00$ & $3 \cdot 60$ \\
\hline 3-Iodo-salicylhydroxamic acid & 3-ISHA & $62 \cdot 02$ & $7 \cdot 33$ & $4 \cdot 26$ \\
\hline 5-Iodo-salicylhydroxamic acid & 5-ISHA & $63 \cdot 72$ & $7 \cdot 33$ & $4 \cdot 26$ \\
\hline 3,5-Diiodo-salicylhydroxamic acid & 3,5-ISHA & $70 \cdot 05$ & $6 \cdot 98$ & $3 \cdot 56$ \\
\hline 3-Methyl-salicylhydroxamic acid & 3-MSHA & $62 \cdot 02$ & $7 \cdot 74$ & $5 \cdot 08$ \\
\hline 5-Methyl -salicylhydroxamic acid & 5-MSHA & $63 \cdot 72$ & $7 \cdot 74$ & $5 \cdot 08$ \\
\hline 3,5-Dimethyl-salicylhydroxamic acid & 3,5-DMSHA & $70 \cdot 05$ & $7 \cdot 80$ & $5 \cdot 20$ \\
\hline 3-Methoxy-salicylhydroxamic acid & 3-MeSHA & $73 \cdot 22$ & $7 \cdot 57$ & $4 \cdot 74$ \\
\hline 5-Methoxy-salicylhydroxamic acid & 5-MeSHA & $78 \cdot 75$ & $7 \cdot 57$ & $4 \cdot 74$ \\
\hline 3,5-Dimethoxy-salicylhydroxamic acid & 3,5-DMeSHA & $95 \cdot 32$ & $7 \cdot 46$ & $4 \cdot 52$ \\
\hline 3-Nitro-salicylhydroxamic acid & 3-NSHA & $83 \cdot 38$ & $6 \cdot 94$ & $3 \cdot 48$ \\
\hline 5-Nitro-salicylhydroxamic acid & 5-NSHA & $87 \cdot 54$ & $6 \cdot 94$ & $3 \cdot 48$ \\
\hline 3,5-Dinitro-salicylhydroxamic acid & 3,5-DNSHA & $114 \cdot 20$ & $6 \cdot 20$ & $2 \cdot 00$ \\
\hline
\end{tabular}

Table 2. Data for linear regression between the logarithm of protonation constants and Wms.

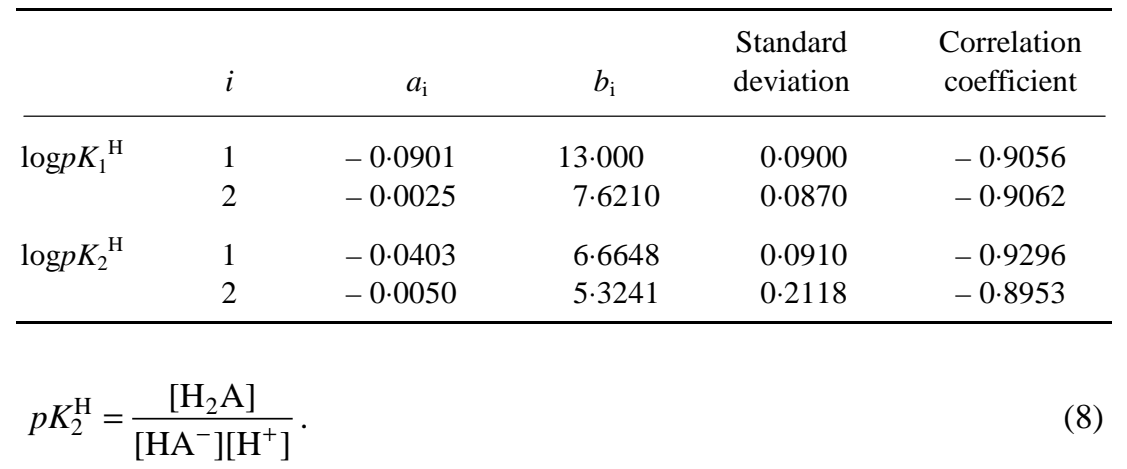

The $p K_{1}{ }^{\mathrm{H}}$ and $p K_{2}{ }^{\mathrm{H}}$ values were determined earlier ${ }^{3}$, by means of previously described experimental techniques ${ }^{12,13}$. It is observed that when Wms is correlated with each of the 
Table 3. Observed and estimated protonation constants for SHA derivatives.

\begin{tabular}{|c|c|c|c|c|c|c|}
\hline \multirow[b]{2}{*}{ Compound } & \multicolumn{3}{|c|}{$\log p K_{1}^{\mathrm{H}}$} & \multicolumn{3}{|c|}{$\log p K_{2}{ }^{\mathrm{H}}$} \\
\hline & Observed & Estimated & Residue & Observed & Estimated & Residue \\
\hline SHA & $9 \cdot 28$ & Outlier & - & $6 \cdot 18$ & Outlier & - \\
\hline 3-ASHA & $7 \cdot 68$ & $7 \cdot 65$ & 0.03 & 4.96 & 4.90 & 0.06 \\
\hline 5-ASHA & $7 \cdot 68$ & $7 \cdot 64$ & 0.04 & 4.96 & $4 \cdot 88$ & 0.08 \\
\hline 3,5-DASHA & $7 \cdot 68$ & $7 \cdot 57$ & $0 \cdot 11$ & 4.96 & $4 \cdot 75$ & $0 \cdot 21$ \\
\hline 3-BSHA & $7 \cdot 29$ & $7 \cdot 41$ & $0 \cdot 12$ & $4 \cdot 18$ & $4 \cdot 16$ & 0.02 \\
\hline 5-BSHA & $7 \cdot 29$ & $7 \cdot 25$ & 0.04 & $4 \cdot 18$ & 4.09 & 0.09 \\
\hline 3,5-DBSHA & $6 \cdot 90$ & $6 \cdot 68$ & $0 \cdot 22$ & $3 \cdot 40$ & $3 \cdot 84$ & -0.44 \\
\hline 3-CSHA & $7 \cdot 31$ & $7 \cdot 41$ & $0 \cdot 10$ & $4 \cdot 22$ & $4 \cdot 16$ & 0.06 \\
\hline 5-CSHA & $7 \cdot 31$ & $7 \cdot 25$ & 0.06 & $4 \cdot 22$ & 4.09 & $0 \cdot 13$ \\
\hline 3,5-DCSHA & $6 \cdot 94$ & $6 \cdot 69$ & $0 \cdot 25$ & $3 \cdot 48$ & $3 \cdot 84$ & $-0 \cdot 36$ \\
\hline 3-FSHA & $7 \cdot 34$ & $7 \cdot 41$ & -0.41 & $4 \cdot 28$ & $4 \cdot 16$ & $0 \cdot 12$ \\
\hline 5-FSHA & $7 \cdot 34$ & $7 \cdot 25$ & 0.09 & $4 \cdot 28$ & $4 \cdot 09$ & $0 \cdot 19$ \\
\hline 3,5-DFSHA & $7 \cdot 00$ & $6 \cdot 69$ & $0 \cdot 31$ & $3 \cdot 60$ & $3 \cdot 84$ & $-0 \cdot 24$ \\
\hline 3-ISHA & $7 \cdot 33$ & $7 \cdot 41$ & -0.08 & $4 \cdot 26$ & $4 \cdot 16$ & $0 \cdot 10$ \\
\hline 5-ISHA & $7 \cdot 33$ & $7 \cdot 25$ & 0.08 & $4 \cdot 26$ & 4.09 & $0 \cdot 17$ \\
\hline 3,5-ISHA & $6 \cdot 98$ & $6 \cdot 69$ & $0 \cdot 29$ & $3 \cdot 56$ & $3 \cdot 84$ & $-0 \cdot 28$ \\
\hline 3-MSHA & $7 \cdot 74$ & $7 \cdot 70$ & 0.04 & 5.08 & $5 \cdot 01$ & 0.07 \\
\hline 5-MSHA & $7 \cdot 74$ & $7 \cdot 70$ & 0.04 & 5.08 & $5 \cdot 00$ & 0.08 \\
\hline 3,5-DMSHA & $7 \cdot 80$ & $7 \cdot 68$ & $0 \cdot 12$ & $5 \cdot 20$ & 4.97 & $0 \cdot 23$ \\
\hline 3-MeSHA & $7 \cdot 57$ & $7 \cdot 67$ & $-0 \cdot 10$ & $4 \cdot 74$ & 4.95 & $-0 \cdot 21$ \\
\hline 5-MeSHA & $7 \cdot 57$ & $7 \cdot 66$ & -0.09 & $4 \cdot 74$ & 4.93 & $-0 \cdot 19$ \\
\hline 3,5-DMeSHA & $7 \cdot 46$ & 7.62 & -0.16 & $4 \cdot 52$ & $4 \cdot 84$ & $-0 \cdot 32$ \\
\hline 3-NSHA & $6 \cdot 94$ & 5.48 & 1.46 & $3 \cdot 48$ & $3 \cdot 30$ & $0 \cdot 18$ \\
\hline 5-NSHA & $6 \cdot 94$ & 5.11 & 1.83 & $3 \cdot 48$ & $3 \cdot 13$ & $0 \cdot 35$ \\
\hline 3,5-DNSHA & $6 \cdot 20$ & $2 \cdot 71$ & $3 \cdot 49$ & $2 \cdot 00$ & $2 \cdot 06$ & -0.06 \\
\hline
\end{tabular}

proton-ligand formation constants, the point belonging to SHA deviate considerably from the linear plots, whereas the other points are grouped into two families, I and II. In the first family are included all the halogen-substituted derivatives together with nitroderivatives. The other family (II) contains amino-, methyl- and methoxy-derivatives of SHA. Statistical analysis has indicated that for both the families, good correlations are obtained.

Hence, the following expressions can be used,

$$
\log p K_{1}^{\mathrm{H}}=a_{1} \mathrm{Wms}+b_{1}
$$

for amino-, methyl- and methoxy-derivatives of SHA and

$$
\log p K_{2}{ }^{\mathrm{H}}=a_{2} \mathrm{Wms}+b_{2} \text {, }
$$

for fluoro-, chloro-, bromo-, iodo- and nitro-substituted SHA.

Calculated values of the coefficients $a_{1}$ and $b_{1}, i=1,2$ in (9) and (10), as well as the data showing the quality of respective correlations are given in table 2 . Perusal of table 2 


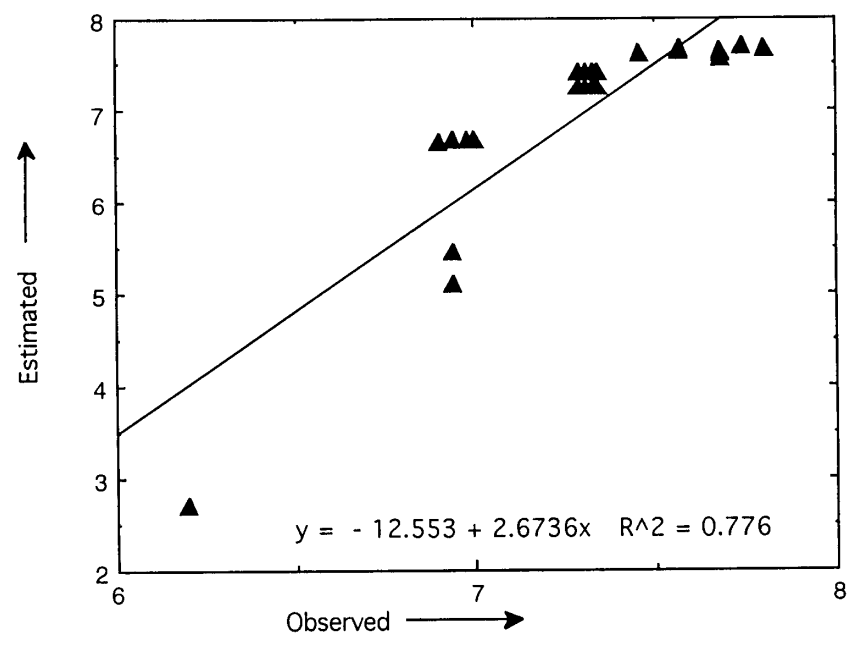

Figure 2. Correlation of observed and estimated $\log p K_{1}{ }^{\mathrm{H}}$ of SHA derivatives used in the present study.

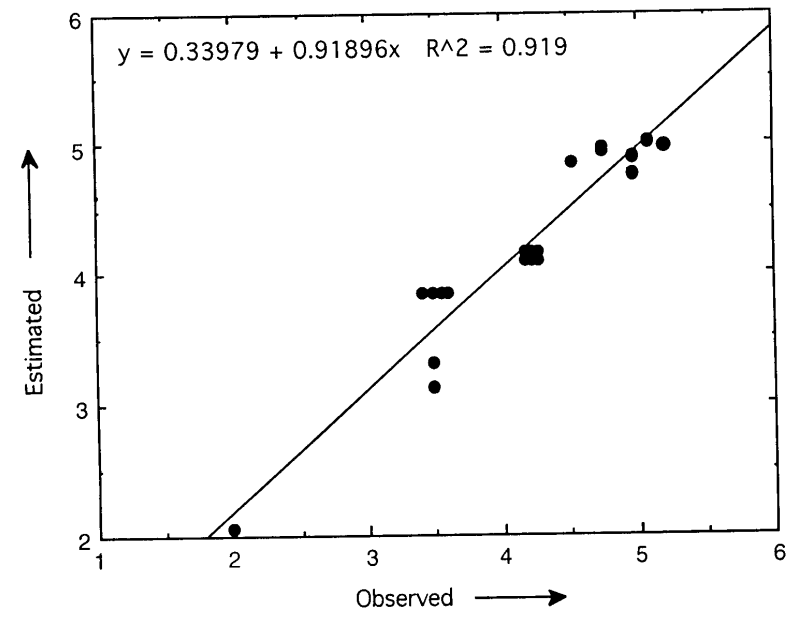

Figure 3. Correlation of observed and estimated $\log p K_{2}{ }^{\mathrm{H}}$ of SHA derivatives used in the present study.

indicates that the proton-ligand formation constants $\left(\log p K_{1}{ }^{\mathrm{H}}\right.$ and $\left.\log p K_{2}^{\mathrm{H}}\right)$ for SHAderivatives can be accurately estimated by means of Wms.

Recent work by us ${ }^{14,15}$ indicates that the pharmacological properties of SHAderivatives are a function of their protonation constants. In view of this and on the basis of the results obtained in the present study, it is possible to use Wms to infer the pharmacological activities of SHA-derivatives.

It is worth mentioning that the categorising of the correlations into two families (I and II) is due to $\pi$-electron-donating and -withdrawing effect of the respective substituents. 
Electron-donating substituents (amino, methyl, methoxy) form the family II while electron-withdrawing substituents (nitro, halogens) belong to family I. It is worthy of mention that the amino- and methoxy-groups are typical $\pi$-donors, whereas the methylgroup increases the electron density in the aromatic nucleus due to hyperconjugation.

Final evidence in favour of our result is obtained by plotting estimated proton-ligand formation constants against their observed values. Such plots are shown in figures 2 and 3 respectively for $\log p K_{1}{ }^{\mathrm{H}}$ and $\log p K_{2}^{\mathrm{H}}$. Results show that the proton-ligand formation constants of the nuclear substituted SHA-derivatives are sensitive to the number, position and shape of the substituents, as reflected by their Wms values.

\section{Acknowledgements}

Our thanks are due to the Indian National Science Academy (INSA) New Delhi and the Hungarian Academy of Sciences (HAS), Budapest for the sanction of an INSA-HAS project.

\section{References}

1. Gale G R, Hyenes J B and Smith A B 1970 J. Med. Chem. 13571

2. Gale G R, Smith A B and Walkas E M 1970 J. Cancer Res. 3024

3. Joshi S 1970 Studies on quantitative structure-activity relationships, $\mathrm{PhD}$ thesis, Devi Ahilya University, Indore

4. Gale G R and Hyenes J B 1968 J. Med. Chem. 11191

5. Kier L B and Hall L H 1976 Molecular connectivity in chemistry and drug research (New York: Academic Press)

6. Kier L B and Hall L H 1986 Molecular connectivity in structure-activity analysis (New York: Wiley)

7. Wiener H 1947 J. Am. Chem. Soc. 6917

8. Gutman I and Polansky O E 1986 Mathematical concept in organic chemistry (New York: Wiley)

9. Trinajestic N 1983 Chemical graph theory (Boca Raton, FL: CRC Press) vols 1 and 2

10. Merrifield R E and Simmons H E 1989 Topological methods in chemistry (NewYork: Academic Press)

11. Balaban A T (ed.) 1976 Chemical applications of graph theory (NewYork: Academic Press)

12. Irving H and Rossotti H S 1953 J. Chem. Soc. 3397

13. Beek M T 1970 Chemistry of complex equilibria (NewYork: Van Nostrand)

14. Khadikar P V, Pol B and Ali S M 1986 Rev. Microbiol. (Sao Paolo) 17291

15. Khadikar P V, Saxena B, Khaddar T and Faroque M A 1994 Indian J. Pharm. Sci. 56215 